ISSN 1561-8331 (Print)

ISSN 2524-2342 (Online)

УДК 547.638.1, 547.853.3, 547.855.3

https://doi.org/10.29235/1561-8331-2021-57-4-431-437

Поступила в редакцию 23.08.2021

Received 23.08.2021

\author{
Д. С. Мартинкевич ${ }^{1}$, Е. Ф. Чернявская ${ }^{2}$, В. А. Тарасевич ${ }^{1}$ \\ ${ }^{1}$ Институт химии новых материалов НАН Беларуси, Минск, Беларусь \\ ${ }^{2}$ Белорусский государственный технологический университет, Минск, Беларусь

\section{СИНТЕЗ ПИРИМИДИНОВЫХ ПРОИЗВОДНЫХ НА ОСНОВЕ ХАЛКОНОВ И ИХ ПРОТИВОМИКРОБНАЯ АКТИВНОСТЬ}

\begin{abstract}
Аннотация. Синтезирован ряд замещенных халконов и пиримидиновых производных на их основе. Исследована противомикробная активность полученных соединений, а также их способность усиливать действие существующих противомикробных средств. Синтезированные на основе халконов пиримидиновые производные обладают антибактериальной и противомикробной активностью, а также способны усиливать противомикробную активность существующих препаратов.

Ключевые слова: халконы, гуанидин, циклоконденсация, пиримидины, противомикробная активность

Для цитирования. Мартинкевич, Д. С. Синтез пиримидиновых производных на основе халконов и их противомикробная активность / Д. С. Мартинкевич, Е. Ф. Чернявская, В. А. Тарасевич // Вес. Нац. акад. навук Беларусі. Сер. хім. навук. - 2021. - Т. 57, № 4. - С. 431-437. https://doi.org/10.29235/1561-8331-2021-57-4-431-437
\end{abstract}

\author{
D. S. Martsinkevich ${ }^{1}$, K. F. Chernyavskaya ${ }^{2}$, V. A. Tarasevich ${ }^{1}$ \\ ${ }^{1}$ Institute of Chemistry of New Materials of the National Academy of Sciences of Belarus, Minsk, Belarus \\ ${ }^{2}$ Belarusian State Technological University, Minsk, Belarus
}

\title{
SYNTHESIS OF CHALCONE-BASED PYRIMIDINE DERIVATIVES AND THEIR ANTIMICROBIAL ACTIVITY
}

\begin{abstract}
A series of substituted chalcones and pyrimidine derivatives on their base was synthesized. Obtained compounds were tested for antimicrobial activity and ability to increase activity of known antimicrobial substances. Pyrimidine products shown good activity against Staphylococcus aureus and Candida tropicalis. These compounds also could increase activity of modified polyguanidines against Staphylococcus aureus.

Keywords: chalcones, guanidine, cyclocondensation, pyrimidines, antimicrobial activity

For citation. Martsinkevich D. S., Chernyavskaya K. F., Tarasevich V. A. Synthesis of chalcone-based pyrimidine derivatives and their antimicrobial activity. Vestsi Natsyyanal'nai akademii navuk Belarusi. Seryya khimichnykh navuk = Proceedings of the National Academy of Sciences of Belarus. Chemical Series, 2021, vol. 57, no. 4, pp. 431-437 (in Russian). https://doi.org/ 10.29235/1561-8331-2021-57-4-431-437
\end{abstract}

Введение. В последнее время прослеживается тенденция к расширению исследований различных природных соединений. Такие вещества, как правило, обладают биологической активностью различного вида, что обуславливает их применение во многих сферах жизнедеятельности человека. Существует потребность в разработке новых веществ с антибактериальной активностью, которая вызвана появлением штаммов бактерий, устойчивых к существующим лекарственным и дезинфицирующим средствам. Новые соединения могут использоваться как самостоятельные противомикробные средства, так и в качестве добавок к существующим препаратам. Для этих целей подходят халконы - природные $\alpha, \beta$-ненасыщенные карбонильные соединения, относящиеся к классу флавоноидов. Как и другие соединения этой группы, халконы проявляют широкий спектр биологической активности [1, 2], а простота синтеза и высокая реакционная способность делает их перспективными исходными веществами для синтеза новых лекарственных препаратов. Исследования по синтезу новых халконов ведутся как в направлении введения в состав халкона различных заместителей $[3,4]$, в том числе и фармакофорных групп, так и в направлении синтеза из халконов новых веществ, прежде всего гетероциклических производных [5-7].

Азотсодержащие гетероциклические вещества широко распространены среди природных продуктов и обладают широким спектром биологической активности. Одним из таких веществ является

(C) Мартинкевич Д. С. , Чернявская Е. Ф., Тарасевич В. А., 2021 
пиримидин, широко встречающийся в живой природе и проявляющий разнообразную биологическую активность [8]. Можно ожидать, что пиримидиновые производные, полученные из халконов, будут обладать увеличенной противомикробной активностью по сравнению с исходными халконами.

Цель настоящей работы - получение новых халконов, синтез из них пиримидиновых производных и изучение противомикробной активности полученных веществ.

Результаты и их обсуждение. Среди описанных в литературе способов синтеза халконов наиболее простым при выполнении и не требующим дорогих реагентов и катализаторов оказался синтез халконов по реакции Кляйзена-Шмидта. Был осуществлен синтез халконов с различными заместителями по методике [9]. Смесь соответствующих бензальдегида, ацетофенона и гидроксида натрия перемешивали в этаноле при комнатной температуре в течение 2 ч (рис. 1). Выходы халконов 1-4 составили 51-78 \%.

Полученные халконы использовали в синтезе замещенных пиримидинов путем циклизации халконов с гидрохлоридом гуанидина. Были использованы условия реакции, описанные в статье [10]. Во взаимодействие с халконом 2 вводили 1,5-кратный избыток гидрохлорида гуанидина и 4,5-кратный избыток твердого $\mathrm{NaOH}$ в этаноле (рис. 2, a). Смесь кипятили в течение 9 ч, а превращение халкона контролировали с помощью ТСХ. Выход продукта 5 составил 70 \%. При взаимодействии халконов 3 и $\mathbf{4}$ с гидрохлоридом гуанидина при указанных выше условиях образовывались соответствующие дигидропиримидины 6, 7 (рис. 2, b) с выходами 75 и $67 \%$ соответственно.

Полученные халконы и их пиримидиновые производные были исследованы на наличие антибактериальной и противогрибковой активности. В качестве тест-культур использовали грибы Aspergillus niger, Penicillium sp., Candida tropicalis и бактерии Escherichia coli ATCC 8739, Staphylococcus aureus ATCC 6538. На первом этапе исследовали способность халконов 1-4 усиливать противомикробное действие известных антибиотиков - стрептомицина и цефотаксима. Было обнаружено, что ни один из халконов не усиливает антибактериальную активность антибиотиков.

На втором этапе исследовали противомикробную активность пиримидина $\mathbf{5}$ и дигидропиримидинов 6, 7. Было показано, что все образцы обладают антибактериальной и противогрибковой активностью (табл. 1). Наиболее чувствительными к исследуемым образцам оказались бактерии

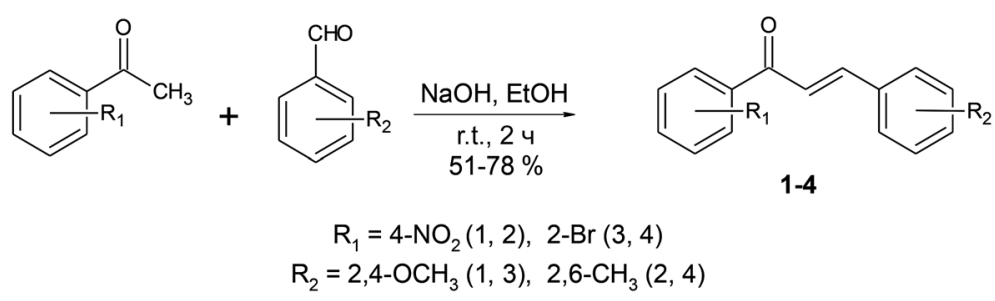

Рис. 1. Схема синтеза халконов по реакции Кляйзена-Шмидта

Fig. 1. Scheme of chalcones synthesis via Claisen-Shmidt reaction

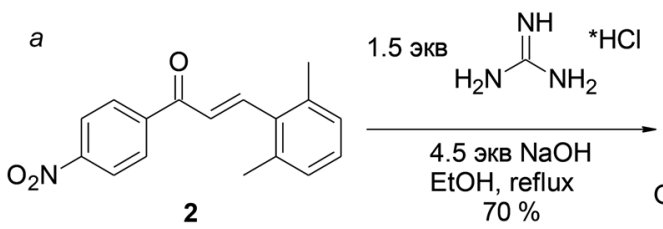<smiles>Cc1cccc(C)c1-c1cc(-c2ccc([N+](=O)[O-])cc2)nc(N)n1</smiles>

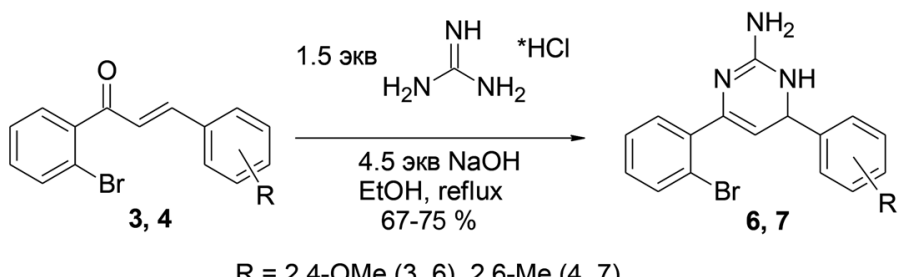

Рис. 2. Взаимодействие халконов 2-4 с гидрохлоридом гуанидина

Fig. 2. Interaction of chalcones $\mathbf{2}-\mathbf{4}$ with guanidine hydrochloride 
Staphylococcus aureus ATCC 6538 и дрожжи Candida tropicalis. Далее изучали синергическое действие данных соединений при совместном использовании с другими противомикробными препаратами - модифицированным полигексаметиленгуанидином (ПГМГ), ампициллином, хлорамфениколом, тетрациклином, цефалексином. Было показано, что пиримидиновые производные 5-7 обладают небольшим эффектом усиления противомикробных свойств исследуемых препаратов (табл. 2). Данный эффект зависит от типа препарата и вида тест-организмов, тем не менее наибольшим эффектом для большинства культур обладали дигидропиримидины 6 и 7.

Т а б л и ц а 1. Результаты исследования противомикробной активности пиримидиновых производных халконов

$\mathrm{T}$ a b 1 e 1. Results of antimicrobial activity evaluation of chalcone-based pyrimidines

\begin{tabular}{|l|c|c|c|c|}
\hline \multirow{2}{*}{ Тест-микроорганизм } & \multicolumn{4}{|c|}{ Диаметр зон ингибирования роста для различных веществ, мм } \\
\cline { 2 - 5 } & $\mathbf{5}$ & $\mathbf{6}$ & $\mathbf{7}$ & DMSO \\
\hline Penicillium sp. & 0 & 0 & 11 & 0 \\
\hline Aspergillus niger & 0 & 0 & 0 & 0 \\
\hline C. tropicalis & 19 & 15 & 16 & 0 \\
\hline E.coli ATCC 8739 & 21 & 13 & 14 & 0 \\
\hline Staphylococcus aureus ATCC 6538 & 34 & 30 & 29 & 0 \\
\hline
\end{tabular}

Т а б л и ц а 2. Результаты оценки синергического влияния пиримидиновых производных на противомикробные препараты (диффузионный метод)

$\mathrm{T}$ a b l e 2. Results of synergetic activity evaluation of synthesized pyrimidines on known antimicrobial substances (by diffusion method)

\begin{tabular}{|c|c|c|c|c|c|c|}
\hline \multicolumn{7}{|c|}{ Диаметр зон ингибирования роста, мм } \\
\hline Вещество & Amp & Chl & Ttc & Cef & ПГмГ & $\begin{array}{c}\text { К - нет антимикробного } \\
\text { агента }\end{array}$ \\
\hline \multicolumn{7}{|c|}{ E. coli ATCC 8739} \\
\hline 5 & 17 & 0 & 13 & 16 & 11 & 0 \\
\hline 6 & 17 & 0 & 12 & 15 & 13 & 0 \\
\hline 7 & 17 & 0 & 0 & 17 & 12 & 0 \\
\hline К - нет халкона & 16 & 12 & 11 & 14 & 0 & \\
\hline \multicolumn{7}{|c|}{ Staphylococcus aureus ATCC 6538} \\
\hline 5 & 11 & 14 & 0 & 0 & 19 & 0 \\
\hline 6 & 11 & 18 & 13 & 0 & 16 & 0 \\
\hline 7 & 12 & 18 & 12 & 12 & 15 & 11 \\
\hline К-нет халкона & 22 & 15 & 16 & 13 & 14 & \\
\hline \multicolumn{7}{|c|}{ Aspergillus niger } \\
\hline 5 & - & - & - & - & 17 & 0 \\
\hline 6 & - & - & - & - & 16 & 0 \\
\hline 7 & - & - & - & - & 14 & 0 \\
\hline К-нет халкона & - & - & - & - & 0 & \\
\hline \multicolumn{7}{|c|}{ Penicillium sp. } \\
\hline 5 & - & - & - & - & 16 & 0 \\
\hline 6 & - & - & - & - & 22 & 16 \\
\hline 7 & - & - & - & - & 22 & 20 \\
\hline К - нет халкона & - & - & - & - & 12 & \\
\hline \multicolumn{7}{|c|}{ C. tropicalis } \\
\hline 5 & - & - & - & - & 16 & 11 \\
\hline 6 & - & - & - & - & 16 & 11 \\
\hline 7 & - & - & - & - & 16 & 12 \\
\hline К - нет халкона & - & - & - & - & 0 & \\
\hline
\end{tabular}

П р и м е ч а н и е. Amp - Ампициллин, Chl - Хлорамфеникол, Ttc - Тетрациклин, Cef - Цефалексин. 
Выявленное усиление действия противомикробных препаратов дополнительно оценивали суспензионным способом. Полученные результаты подтвердили наличие эффекта усиления противомикробных свойств модифицированного ПГМГ при совместном культивировании с растворами пиримидиновых производных. Наилучшие результаты были получены для тест-культуры Staphylococcus aureus ATCC 6538 и соединения 7 (табл. 3).

Т а б л и ц а 3. Результаты оценки синергического влияния полученных пиримидиновых производных на противомикробные препараты (суспензионный метод)

$\mathrm{T}$ a b 1 e 3. Evaluation of synergetic activity of synthesized pyrimidines on known antimicrobial substances (by suspension method)

\begin{tabular}{|l|c|c|c|c|c|c|c|}
\hline \multirow{2}{*}{} & \multicolumn{6}{|c|}{ Концентрация жизнеспособных клеток S. аureus АТСС 6538 при высеве из разведений, КОЕ/мл } & \multirow{2}{*}{ FR } \\
\cline { 2 - 6 } & $10^{0}$ & $10^{-1}$ & $10^{-2}$ & $10^{-3}$ & $10^{-4}$ & $10^{-5}$ & \\
\hline Положительный контроль (К+) & - & - & - & $1,7 \times 10^{7}$ & - & $2,6 \times 10^{7}$ & - \\
\hline ПГМГ $(0,0005 \%)$ & газон & - & $3,3 \times 10^{5}$ & - & - & - & 1,9 \\
\hline $5(0,005 \%)$ & газон & - & $1,7 \times 10^{5}$ & - & - & - & 2,2 \\
\hline $6(0,005 \%)$ & $9,8 \times 10^{3}$ & - & $2,4 \times 10^{4}$ & - & - & - & 3,0 \\
\hline $7(0,005 \%)$ & $7,7 \times 10^{3}$ & - & $8,4 \times 10^{3}$ & - & - & - & 3,5 \\
\hline $5(0,005 \%)+$ ПГМГ $(0,0005 \%)$ & $3,4 \times 10^{4}$ & - & $2,6 \times 10^{4}$ & - & - & - & 2,9 \\
\hline $6(0,005 \%)+$ ПГМГ $(0,0005 \%)$ & $4,7 \times 10^{3}$ & - & $5,0 \times 10^{3}$ & - & - & - & 3,7 \\
\hline $7(0,005 \%)+$ ПГМГ $(0,0005 \%)$ & $4,5 \times 10^{2}$ & - & - & - & - & - & 4,7 \\
\hline
\end{tabular}

Экспериментальная часть. Использованные в работе реактивы и растворители имели квалификацию «ч.» и «ч. д. а.». Спектры ЯМР ${ }^{1} \mathrm{H}$ и ${ }^{13} \mathrm{C}$ записаны на спектрометре BrukerAvance-500 в $\mathrm{CDCl}_{3}, \mathrm{DMSO}-\mathrm{d} 6$, внутренний стандарт - TMC, рабочая частота $500 \mathrm{MГц} \mathrm{для}{ }^{1} \mathrm{H}$ и 125 МГц для ${ }^{13} \mathrm{C}$. ИК-спектры записаны в таблетке из $\mathrm{KBr}$ на ИК-Фурье спектрометре Bruker Tensor-27. Температуры плавления определяли с помощью прибора MPA100 OptiMelt. Тонкослойную хроматографию проводили на пластинках Kieselgel 60F 254 (Merck) в системе этилацетат : гексан, $1: 2$.

(Е)-1-(4-нитрофенил)-3-(2,4-диметоксифенил)проп-2-ен-1-он 1. В 50-мл колбу вносили 1,06 г (6,4 ммоль) 1-(4-нитрофенил)этанона, 1,06 г (6,4 ммоль) 2,4-диметоксибензальдегида, 0,26 г (6,4 ммоль) гидроксида натрия и 30 мл этилового спирта. Смесь перемешивали при комнатной температуре в течение 2 ч (контроль по ТСХ). Образовавшуюся суспензию выливали в 80 мл ледяной воды и нейтрализовывали разбавленной соляной кислотой. Выпавший осадок отфильтровывали на стеклянном фильтре, промывали водой, этиловым спиртом и снова водой. Полученный продукт использовали далее без дополнительной очистки. Выход 1,55 г (77,5 \%) - желтый поро-

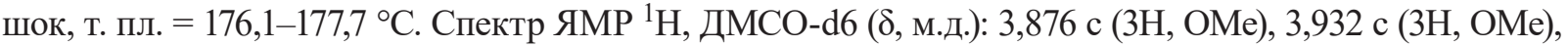
6,669 д ( $2 \mathrm{H}, \mathrm{HAr}), 7,794$ д $(1 \mathrm{H}, \mathrm{C}=\mathrm{CH}), 7,971$ д $(1 \mathrm{H}, \mathrm{HAr}), 8,061$ д $(1 \mathrm{H}, \mathrm{C}=\mathrm{CH}), 8,321$ д (2H, HAr), 8,383 д (2Н, HAr); Спектр ЯМР ${ }^{13} \mathrm{C}$, ДМСО-d6 ( $\delta$, м.д.): 56,11, 56,41 (OMe), 98,79, 107,06, 116,14, 119,22 (CAr), 124,33 (C=C), 130,12, 131,04, 140,84 (CAr), 143,45 (C=C), 150,12, 160,80, 164,13 (CAr), $188,69(\mathrm{C}=\mathrm{O})$. ИК-спектр, $\mathrm{KBr}\left(\bar{v}, \mathrm{~cm}^{-1}\right): 3111,71$ сл $\left(\mathrm{C}_{\mathrm{Ar}}-\mathrm{H}\right), 3004,81$ сл $(=\mathrm{C}-\mathrm{H}), 2842,68$ сл $(\mathrm{OMe})$, 1657,48 с $(\mathrm{C}=\mathrm{O}), 1605,12$ с $(\underline{\mathrm{C}=\mathrm{C}}-\mathrm{CO}), 1587,36$ c, 1562,01 c, 1522,35 с (фенил), 1507,11 cp (N-O), 1454,97 ср $\delta(\mathrm{CH}-\mathrm{O}), 1443,12$ ср (фенил), 1342,82 с (N-O), 1312,19 с, 1295,05 с $(=\mathrm{C}-\mathrm{H}), 1258,62$ c $\left(\mathrm{C}_{\mathrm{Ar}}-\mathrm{OMe}\right), 1217,75 \mathrm{c}, 1193,57 \mathrm{cp}\left(\mathrm{C}_{\mathrm{Ar}}-\mathrm{H}\right), 1108,28$ сл, 1041,35 c, 1024,65 c, 1010,66 ср $\left(\mathrm{C}_{\mathrm{Ar}}-\mathrm{H}\right)$, $988,39 \mathrm{cp}(=\mathrm{C}-\mathrm{H}), 875,40$ сл, 851,85 с $\left(\mathrm{C}_{\mathrm{Ar}}-\mathrm{H}\right), 837,16 \mathrm{c}\left(\mathrm{Ar}-\mathrm{NO}_{2}\right)$.

(2Е)-1-(4-нитрофенил)-3-(2,6-диметилфенил)проп-2-ен-1-он 2. В 50-мл колбу вносили 1,17 г (7,1 ммоль) 1-(4-нитрофенил)этанона, 0,95 г (7,1 ммоль) 2,6-диметилбензальдегида, 0,384 г (9,6 ммоль) гидроксида натрия и 30 мл этилового спирта. Смесь перемешивали при комнатной температуре в течение 2 ч (контроль по ТСХ). Реакционную смесь выливали в 80 мл ледяной воды и нейтрализовывали разбавленной соляной кислотой. Выпавший осадок отфильтровывали на стеклянном фильтре, промывали водой, этанолом и снова водой. Полученный сырой продукт сушили на воздухе и перекристаллизовывали из 21 мл этанола. Выход 1,21 г (60,5 \%) - оранжевый порошок, т. пл. $=113,2-115,4{ }^{\circ} \mathrm{C}$. Спектр ЯМР ${ }^{1} \mathrm{H}$, ДМСО-d6 ( $\delta$, м.д.): 2,407 с $\left(6 \mathrm{H}, 2 \mathrm{CH}_{3}\right), 7,162$ д (2H, HAr), 7,219 м (1H, HAr), 7,446 д (1H, C=CH), 7,919 д (1H, C=CH), 8,311 д (2H, HAr), 8,386 д (2H, HAr). 
Спектр ЯМР ${ }^{13} \mathrm{C}$, ДМСО-d6 (б, м.д.): 21,30 $\left(2 \mathrm{CH}_{3}\right), 124,41(\mathrm{C}=\mathrm{C}), 128,05,128,81,129,28,130,42,134,28$, 137,39 (CAr), 142,13 (C=C), 150,35 (CAr), $189,10(\mathrm{C}=\mathrm{O})$. ИК-спектр, $\mathrm{KBr}\left(\bar{v}, \mathrm{~cm}^{-1}\right)$ : 3105,07 сл $(=\mathrm{C}-\mathrm{H}), 2964$, 23 сл $\left(\mathrm{CH}_{3}\right), 1661,40$ с $(\mathrm{C}=\mathrm{O}), 1585,59 \mathrm{c}(\mathrm{C}=\mathrm{C}-\mathrm{CO}), 1520,83 \mathrm{c}(\mathrm{N}-\mathrm{O}), 1467,34 \mathrm{cp}\left(\mathrm{CH}_{3}\right), 1382,94$ сл $\left(\mathrm{CH}_{3}\right)$, 1343,88 с (N-O), 1195,30 cp, 1172,11 cp, 1107,50 сл, 1026,38 cp, 1009,40 cp $\left(\mathrm{C}_{\mathrm{Ar}}-\mathrm{H}\right), 853,12$ c, 776,62 cp, $698,90 \mathrm{cp}\left(\mathrm{C}_{\mathrm{Ar}}-\mathrm{H}\right)$.

(2Е)-1-(2-бромофенил)-3-(2,4-диметоксифенил)проп-2-ен-1-он 3. В 50-мл колбу вносили 1,15 г (5,76 ммоль) 1-(2-бромофенил)этанона, 0,96 г (5,76 ммоль) 2,4-диметоксибензальдегида, 0,34 г (8.5 ммоль) гидроксида натрия и 25 мл этилового спирта. Смесь перемешивали при комнатной температуре в течение 2 ч (контроль по ТСХ). Реакционную смесь выливали в 10 мл воды и нейтрализовывали разбавленной соляной кислотой. Выпавший осадок отфильтровывали на стеклянном фильтре, промывали водой, этиловым спиртом и снова водой. Полученный сырой продукт сушили на воздухе и перекристаллизовывали из 17 мл этанола. Выход 1,50 г (75,0 \%) желтые кристаллы, т. пл. $=92,1-92,6{ }^{\circ} \mathrm{C}$. Спектр ЯМР ${ }^{1} \mathrm{H}$, ДМСО-d6 ( $\delta$, м.д.): 3,841 с (3H, ОМе), 3,849 с (3H, OMe), 6,621 дд (1H, HAr), 6,640 д (1H, HAr), 7,110 д (1H, C=CH), 7,456 дд (1H, HAr), 7,481 м (1H, HAr), 7,499 д (1H, HAr), 7,526 дд (1H, HAr), 7,566 д (1H, C=CH), 7,753 дд (2H, HAr). Спектр ЯМР ${ }^{13} \mathrm{C}$, ДМСО-d6 (ठ, м.д.): 56,09, 56,38 (OMe), 98,85, 107,03, 115,71 (CAr), 119,04 (C=C), $124,05,128,27,129,43,131,09,132,02,133,55$ (CAr), 141,73 (C=C), 141,99, 160,46, 164,02 (CAr), 194,77 (C=O). ИК-спектр, $\mathrm{KBr}\left(\bar{v}, \mathrm{~cm}^{-1}\right): 3043,67$ сл $(\mathrm{C}-\mathrm{H})_{\mathrm{Ar}}, 3004,63$ сл (=С-H), 2964,51 сл (ОС-Н), 2831,06 сл (ОС-Н), $1625,44$ с $(\mathrm{C}=\mathrm{O}), 1589,08$ оч.с ( $\mathrm{C}=\mathrm{C}-\mathrm{CO}), 1505,36 \mathrm{cp}, 1465,82 \mathrm{cp}$ (фенил), 1452,33 cp, 1336,77 сл. (CH-O), 1293,99 с $(=\mathrm{C}-\mathrm{H}), 1278,40$ оч. с, 1253,12 оч. с $\left(\mathrm{C}_{\mathrm{Ar}}-\mathrm{OMe}\right), 1172,59 \mathrm{cp}, 1121,88$ сл, 1099,63 с, 1029,29 с $\left(\mathrm{C}_{\mathrm{Ar}}-\mathrm{H}\right)$, $986,98 \mathrm{cp}, 874,33$ сл, 827,43 cp, 759,49 ср, 743,70 сл $\left(\mathrm{C}_{\mathrm{Ar}}-\mathrm{H}\right), 591,37 \mathrm{cp}(\mathrm{C}-\mathrm{Br})$.

(2Е)-1-(2-бромофенил)-3-(2,6-диметилфенил)проп-2-ен-1-он 4. В 50-мл колбу вносили 0,86 мл (6,35 ммоль) 1-(2-бромофенил)этанона, 0,85 г (6,35 ммоль) 2,6-диметилбензальдегида, 0,37 г (9,4 ммоль) гидроксида натрия и 20 мл этилового спирта. Смесь перемешивали при комнатной температуре в течение 2 ч (контроль по ТСХ). Реакционную смесь выливали в 50 мл воды и нейтрализовывали разбавленной соляной кислотой. Выпавший осадок отфильтровывали на стеклянном фильтре и промывали водой. Полученный сырой продукт перекристаллизовывали из 2 мл этанола. Выход 1,02 г (51,0 \%) - бежевый порошок, т. пл. $=52,1-53,3{ }^{\circ} \mathrm{C}$. Спектр ЯМР ${ }^{1} \mathrm{H}$,

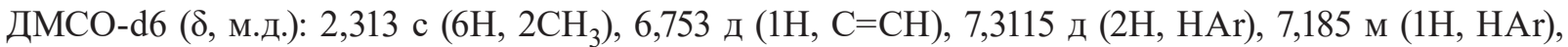
7,455 с (1H, HAr), 7,489 с (1H, HAr), 7,565 дд $(2 \mathrm{H}, \mathrm{HAr}), 7,773$ д (1Н, C=CH). Спектр ЯМР ${ }^{13} \mathrm{C}$, ДМСО-d6 ( $\delta$, м.д.): 21,14 (2 $\left.\mathrm{CH}_{3}\right), 118,97(\mathrm{C}=\mathrm{C}), 128,38,128,81,129,40,129,55,132,16,132,37,133,58$, 137,01 (CAr), 141,00 (C=C), 145,88 (CAr), 194,95 (C=O). ИК-спектр, $\mathrm{KBr}\left(\bar{v}, \mathrm{~cm}^{-1}\right): 2918,10$ сл $(\mathrm{C}-\mathrm{H})_{\mathrm{Ar}}$, $1654,67 \mathrm{c}(\mathrm{C}=\mathrm{C}-\mathrm{CO}), 1619.47 \mathrm{c}(\mathrm{C}=\mathrm{O}), 1588,36 \mathrm{cp}, 1464,63 \mathrm{cp}$ (фенил), 1426,57 cp $\left(\mathrm{C}_{\mathrm{Ar}}-\mathrm{CH}_{3}\right), 1378,05$ сл $\left(\mathrm{C}_{\mathrm{Ar}}-\mathrm{CH}_{3}\right), 1289,62$ с $(=\mathrm{C}-\mathrm{H}), 1248,98 \mathrm{cp}, 1161,25$ сл, 1121,16 сл, 1100,83 cp, 1025,19 ср $\left(\mathrm{C}_{\mathrm{Ar}}-\mathrm{H}\right)$, $989,16 \mathrm{cp}(=\mathrm{C}-\mathrm{H}), 785,16 \mathrm{cp}, 771,30 \mathrm{cp}, 759,60 \mathrm{cp}, 736,49 \mathrm{cp}, 657,43$ сл $\left(\mathrm{C}_{\mathrm{Ar}}-\mathrm{H}\right), 615,28 \mathrm{cp}(\mathrm{C}-\mathrm{Br})$.

4-(2,6-диметилфенил)-6-(4-нитрофенил)пиримидин-2-амин 5. В 50-мл колбу вносили 0,30 г (1,07 ммоль) халкона 2, 0,15 г (1,6 ммоль) гидрохлорида гуанидина, 0,19 г (4,8 ммоль) гидроксида натрия и 10 мл этанола. Смесь кипятили 7 ч (контроль по ТСХ), выливали в ледяную воду и нейтрализовывали разбавленной соляной кислотой. Выпавший осадок отфильтровывали на стеклянном фильтре, промывали водой, этиловым спиртом и сушили на воздухе, затем - 20 мин при $100{ }^{\circ} \mathrm{C}$. Дополнительную очистку продукта не проводили. Выход 0,24 г (70,2 \%) - оранжевый порошок, т. пл. $=115,2{ }^{\circ} \mathrm{C}$, разл. Спектр ЯМР ${ }^{1} \mathrm{H}$, ДМСО-d6 ( $\delta$, м.д.): 2,138 м $\left(6 \mathrm{H}, 2 \mathrm{CH}_{3}\right), 2,198 \mathrm{c}\left(\mathrm{NH}_{2}\right)$, 6,861 д (1H, HAr), 6,951 д(1H, HAr), 7,153 д (2H, HAr), 7,230 д (1H, HAr), 8,270 д (1H, HAr), 8,364 т (1H, HAr), 8,422 с (1H, H-hetAr). Спектр ЯМР ${ }^{13} \mathrm{C}$, ДМСО-d6 ( $\delta$, м.д.): 20,17 $\left(\mathrm{CH}_{3}\right), 123,02,124,29$, $127,83,128,35,12,65,134,99,164,65$ (CAr). ИК-спектр, $\mathrm{KBr}\left(\bar{v}, \mathrm{~cm}^{-1}\right): 3387,38 \mathrm{cp}\left(\mathrm{NH}_{2}\right), 2921,54$ сл (OC-H), 1601,15 с (фенил, $\left.\mathrm{NH}_{2}\right), 1518,41$ с $, 1465,43$ ср (фенил), 1339,41 с $\left(\mathrm{C}_{\mathrm{Ar}}-\mathrm{NH}_{2}\right), 1176,84$ сл, 1108,58 сл, 1031,93 сл, 967,76 сл $\left(\mathrm{C}_{\mathrm{Ar}}-\mathrm{H}\right), 854,48 \mathrm{cp}\left(\mathrm{C}_{\mathrm{Ar}}-\mathrm{H}\right), 744,09$ оч. с $\left(\mathrm{NH}_{2}\right), 521,89$ сл $(\mathrm{C}-\mathrm{Br})$.

4-(2-бромофенил)-6-(2,4-диметоксифенил)-1,6-дигидрпопиримидин-2-амин 6. В 25-мл колбу вносили 0,35 г (1,00 ммоль) халкона 3, 0,14 г (1,5 ммоль) гидрохлорида гуанидина, 0,18 г (4,5 ммоль) гидроксида натрия и 10 мл этанола. Смесь кипятили 9 ч (контроль по ТСХ), выливали в ледяную воду и нейтрализовывали разбавленной соляной кислотой. Выпавший осадок отфильтровывали на фильтре Шотта, промывали водой, этиловым спиртом и снова водой, сушили на воздухе. До- 
полнительную очистку продукта не проводили. Выход 0,29 г (75,1 \%) - светло-бежевый порошок, т. пл. $=88,4-88,8{ }^{\circ} \mathrm{C}$. Спектр ЯМР ${ }^{1} \mathrm{H}, \mathrm{CDCl}_{3}$ ( $\delta$, м.д.): 3,854 с (3H, OMe), 3,865 с (3H, OMе), 5,545 с $\left(2 \mathrm{H}, \mathrm{NH}_{2}\right), 6,504$ д (1H, HAr), 6,566 дд(1H, HAr), 7,160 тд (1H, H-hetAr), 7,289 д (1H, HAr), 7,448 дд (1H, HAr), 7,547 д (1H, HAr), 7,600 д (1H, HAr). Спектр ЯMP ${ }^{13} \mathrm{C}, \mathrm{CDCl}_{3}(\delta$, м.д.): 48,39, 55,39 (OMe), 98,68, 104,24, 122,22, 124,65, 127,25, 128,91 (CAr), 129, 26 (ㄷ-H hetAr), 130,53, 133,07 (CAr), 152,57 (C-N hetAr), 157,38 (CAr), 160,55 (C-N hetAr).

4-(2-бромофенил)-6-(2,6-диметилфенил)-1,6-дигидрпопиримидин-2-амин 7. В 25-мл колбу вносили 0,32 г (1,02 ммоль) соединения 4, 0,14 г (1,5 ммоль) гидрохлорида гуанидина, 0,18 г (4,55 ммоль) гидроксида натрия и 10 мл этанола. Смесь кипятили 9 ч (контроль по ТСХ), выливали в ледяную воду и нейтрализовывали разбавленным раствором $\mathrm{HCl}$. Выпавший осадок отфильтровывали на фильтре Шотта, промывали водой, этанолом и снова водой, сушили на воздухе, затем - 20 мин при $100{ }^{\circ} \mathrm{C}$. Дополнительную очистку продукта не проводили. Выход 0,24 г (66,8 \%) - коричневые кристаллы, т. пл. $=95,5{ }^{\circ} \mathrm{C}$, разл. Спектр ЯМР ${ }^{1} \mathrm{H}$, ДМСО-d6 $(\delta$, м.д.): 2,129 с $(1 \mathrm{H}, \mathrm{NH})$, 2,466 с $\left(6 \mathrm{H}, 2 \mathrm{CH}_{3}\right), 4,549$ д (1H, CH), 5,880 д (1H, C=CH), 7,036 д (2H, HAr), 7,064 д (1H, HAr), 7,190 д $(1 \mathrm{H}, \mathrm{HAr}), 7,339$ д (1Н, HAr), 7,399 д (1Н, HAr), 7,566 д (1Н, HAr). Спектр ЯМР ${ }^{13} \mathrm{C}$, ДМСО-d6 ( $\delta$, м.д.): $20,51\left(\mathrm{CH}_{3}\right), 51,54(\mathrm{CH}), 99,01(=\mathrm{CH}), 121,62,127,38,127,68,127,79,129,21,129,75,130,96,133,13$, 140,56, 154,24 (CAr).

Биологические испытания. Диффузионный метод. На поверхности агара, засеянного тесторганизмами, готовили лунки ( $\varnothing 10$ мм). В лунки вносили по 200 мкл анализируемых образцов (концентрация $0,0005-1,0000 \%$ ). Посевы в течение 2 ч выдерживали в холодильнике, затем инкубировали при $30{ }^{\circ} \mathrm{C}$ в течение $24-48$ ч. Определяли ширину зон ингибирования роста культур.

Суспензионный метод. Суточную культуру (2 мл), разведенную до концентрации $10^{5} \mathrm{KOE} / \mathrm{Mл}$ в питательном бульоне, инкубировали с анализируемыми препаратами различных концентраций $(0,0005-0,005 \%)$ в течение 6 ч. После инкубации осуществляли высев на плотную питательную среду. Результаты оценивали через 24-48 ч. Оценку антимикробной активности проводили по показателю FR:

$$
\mathrm{FR}=\log \left(C_{\text {конт }} / C_{\text {обр }}\right)
$$

где $C_{\text {конт }}$ - концентрация клеток после инкубирования контроля (КОЕ/мл); $C_{\text {обр }}-$ концентрация клеток после инкубирования опытного образца (КОЕ/мл).

Заключение. Были получены четыре халкона с различными заместителями в бензольных кольцах, два из них - $\mathbf{2}$ и $\mathbf{4}$ - синтезированы впервые. На их основе были синтезированы новые пиримидиновые производные: пиримидин 5 и дигидропиримидины 6 и 7. Изучена противомикробная активность полученных веществ и синергетическое действие по отношению к известным противомикробным средствам. Установлено, что пиримидиновые производные на основе халконов обладают противомикробной активностью, наиболее сильно по отношению к бактериям Staphylococcus aureus ATCC 6538 и дрожжам Candida tropicalis. Также полученные гетероциклические соединения обладают способностью усиливать действие противомикробных препаратов, в частности модифицированного ПГМГ. Наиболее активным из пиримидиновых производных является дигидропиримидин 7. Таким образом, гетероциклические производные на основе халконов могут обладать более сильной, чем у халконов, биологической активностью. Это делает халконы перспективными исходными веществами для поиска и синтеза новых противомикробных средств.

\section{Список использованных источников}

1. Recent developments in biological aspects of chalcones: the odyssey continues / A. Rani [et al.] // Expert Opinion on Drug Discovery. - 2019. - Vol. 14, N 3. - P. 249-288. https://doi.org/10.1080/17460441.2019.1573812

2. Chalcone synthesis, properties and medicinal applications: a review / A. Rammohan [et al.] // Environ Chem Lett. 2020. - Vol. 18, N 2. - P. 433-458. https://doi.org/10.1007/s10311-019-00959-w

3. Synthesis and antibacterial evaluation of novel cationic chalcone derivatives possessing broad spectrum antibacterial activity / W.-C. Chu [et al.] // European Journal of Medicinal Chemistry. - 2018. - Vol. 143 - P. 905-921. https://doi.org/ 10.1016/j.ejmech.2017.12.009

4. Synthesis, crystal structure and antimicrobial potential of some fluorinated chalcone-1,2,3-triazole conjugates / P. Yadav [et al.] // European Journal of Medicinal Chemistry. - 2018. - Vol. 155. - P. 263-274. https://doi.org/10.1016/j.ejmech.2018.05.055 
5. Microwave assisted synthesis of chalcone and its polycyclic heterocyclic analogues as promising antibacterial agents: In vitro, in silico and DFT studies / S. A. Khan [et al.] // Journal of Molecular Structure. - 2019. - Vol. 1190 - P. 77-85. https://doi.org/10.1016/j.molstruc.2019.04.046

6. Synthesis and Utility of $\alpha, \beta$-Unsaturated Ketone Bearing Naphthalene and Benzofuran Rings in the Synthesis of Some N-heterocycles with Their Antiviral and Antitumor Activity Evaluation: Synthesis and Utility of Naphthalene-Benzofuran Chalcone in the Synthesis of New Heterocycles / R. S. Gouhar [et al.] // J. Heterocyclic Chem. - 2018. - Vol. 55, N 10. P. 2368-2380. https://doi.org/10.1002/jhet.3301

7. Design, Synthesis, and Biological Evaluation of Novel Pyrazole, Oxazole, and Pyridine Derivatives as Potential Anticancer Agents Using Mixed Chalcone / M. H. Ahmed [et al.] // J. Heterocyclic Chem. - 2019. - Vol. 56, N 1. - P. 114-123. https://doi. $\operatorname{org} / 10.1002 /$ jhet. 3380

8. Pyrimidine candidate as promising scaffold and their biological evaluation / J. Alam [et al.] // Int. J. Pharmacol. Pharm. Sci. - 2015. - Vol. 2, N 4. - P. 55-69.

9. Синтез и противомикробная активность халконов с бензотриазолилметильными и имидазолилметильными заместителями / Л. В. Тинь [и др.] // ЖОрХ. - 2014. - Т. 50, № 12. - С. 1786-1793.

10. Synthesis, antiviral, antituberculostic, and antibacterial activities of some novel, 4-(4-substituted phenyl)-6-(4-nitrophenyl)2-(substituted imino)pyrimidines / A. A. Siddiqui [et al.] // Arch. Pharm. Chem. - 2007. - Vol. 340, N 2. - P. 95-102. https://doi.org/10.1002/ardp.200600121

\section{References}

1. Rani A., Anand A., Kumar K., Kumar V. Recent developments in biological aspects of chalcones: the odyssey continues. Expert Opinion on Drug Discovery, 2019, vol. 14, no. 3, pp. 249-288. https://doi.org/10.1080/17460441.2019.1573812

2. Rammohan A., Reddy J. S., Sravya G., Rao C. N., Zyryanov G. V. Chalcone synthesis, properties and medicinal applications: a review. Environmental Chemistry Letters, 2020, vol. 18, no. 2, pp. 433-458. https://doi.org/10.1007/s10311-019-00959-w

3. Chu W.-C., Bai P.-Y., Yang J.-Q., Cui D.-Y., Hua Y.-G., Yang Y., Yang Q.-Q., Zhang E. Qin S. Synthesis and antibacterial evaluation of novel cationic chalcone derivatives possessing broad spectrum antibacterial activity. European Journal of Medicinal Chemistry,2018, vol. 143, pp. 905-921. https://doi.org/10.1016/j.ejmech.2017.12.009

4. Yadav P., Lal K., Kumar L., Kumar A., Kumar A., Paul A. K., Kumar R. Synthesis, crystal structure and antimicrobial potential of some fluorinated chalcone-1,2,3-triazole conjugates. European Journal of Medicinal Chemistry, 2018. vol. 155, pp. 263-274. https://doi.org/10.1016/j.ejmech.2018.05.055

5. Khan S. A., Asiri A.M., Al-Ghamdi N. S. M., Asad M., Zayed M. E. M., Elroby S. A. K., Aqlan F. M., Wani M. Y., Sharma K. Microwave assisted synthesis of chalcone and its polycyclic heterocyclic analogues as promising antibacterial agents: In vitro, in silico and DFT studies. Journal of Molecular Structure, 2019, vol. 1190, pp. 77-85. https://doi.org/10.1016/j. molstruc.2019.04.046

6. Gouhar R. S., Ewies E. F., El-Shehry M. F., Shaheen M. N. F., Ibrahim E.-M. M. E. Synthesis and Utility of $\alpha, \beta$-Unsaturated Ketone Bearing Naphthalene and Benzofuran Rings in the Synthesis of Some N -heterocycles with Their Antiviral and Antitumor Activity Evaluation: Synthesis and Utility of Naphthalene-Benzofuran Chalcone in the Synthesis of New Heterocycles. Journal of Heterocyclic Chemistry, 2018, vol. 55, pp. 2368-2380. https://doi.org/10.1002/jhet.3301

7. Ahmed M. H., El-Hashash M. A., Marzouk M. I., El-Naggar A. M. Design, Synthesis, and Biological Evaluation of Novel Pyrazole, Oxazole, and Pyridine Derivatives as Potential Anticancer Agents Using Mixed Chalcone. Journal of Heterocyclic Chemistry, 2019, vol. 56, pp. 114-123. https://doi.org/10.1002/jhet.3380

8. Alam J., Alam O., Shrivastava N., Naim M., Alam P. Pyrimidine candidate as promising scaffold and their biological evaluation. International Journal of Pharmacology and Pharmaceutical Sciences, 2015, vol. 2, no. 4, pp. 55-69.

9. Chinh L V., Hung T. N., Nga N. T., Hang T. T. N., Mai T. T. N. Tarasevich V. A. Synthesis and antimicrobial activity of chalcones containing benzotriazolylmethyl and imidazolylmethyl substituents. Russian Journal of Organic Chemistry, 2014, vol. 50, no. 12, pp. 1767-1774. https://doi.org/ 10.1134/S1070428014120094

10. Siddiqui A. A., Rajesh R., Mojahid-Ul-Islam, Alagarsamy V., De Clercq E. Synthesis, Antiviral, Antituberculostic, and Antibacterial Activities of Some Novel, 4-(4-substituted phenyl)-6-(4-nitrophenyl)-2-(substituted imino)pyrimidines. Archiv der Pharmazie - Chemistry in Life Sciences, 2007, vol. 340, no. 2, pp. 95-102. https://doi.org/10.1002/ardp.200600121

\section{Информация об авторах}

Мартинкевич Денис Сергеевич - мл. науч. сотрудник. Институт химии новых материалов НАН Беларуси (ул. Ф. Скорины, 36, 220141, Минск, Республика Беларусь). E-mail: den13martinkevich@gmail.com

Чернявская Екатерина Федоровна - ассистент кафедры биотехнологии. Белорусский государственный технологический университет, (ул. Свердлова, 13 a, 220006, Минск, Республика Беларусь). E-mail: chernyavskaya@belstu.by

Тарасевич Владимир Александрович - д-р хим. наук, профессор, гл. науч. сотрудник. Институт химии новых материалов НАН Беларуси (ул. Ф. Скорины, 36, 220141, Минск, Республика Беларусь). E-mail: $\operatorname{tar@ichnm.by~}$

\section{Information about the authors}

Denis S. Martsinkevich - Junior Researcher. Institute of Chemistry of New Materials of the National Academy of Sciences of Belarus (36, F. Skaryna str., 220141, Minsk, Republic of Belarus). E-mail: den13martinkevich@gmail.com

Katerina F. Chernyavskaya - Assistant of Biotechnology Department. Belarusian State Technological University (13 a, Sverdlova str., 220006, Minsk, Republic of Belarus). E-mail: chernyavskaya@belstu.by

Vladimir A. Tarasevich -D. Sc. (Chemistry), Professor, Chief Researcher. Institute of Chemistry of New Materials of the National Academy of Sciences of Belarus (36, F. Skaryna str., 220141, Minsk, Republic of Belarus). E-mail: tar@ichnm.by 